\title{
Head of the Tibia
}

National Cancer Institute

\section{Source}

National Cancer Institute. Head of the Tibia. NCI Thesaurus. Code C32722.

The superior portion of the tibia that joins with the fibula, femur and patella at the knee joint. 